\title{
Clinical and epidemiological findings in patients with pandemic A (H1N1) 2009 influenza in uppsala county, Sweden
}

\author{
Staffan P.E. Sylvan ${ }^{1,2^{*}}$, Brith Christenson', Karlis Pauksen² and Lars Berglund ${ }^{3}$ \\ *Correspondence: staffan.sylvan@lul.se \\ 'Department of Communicable Disease Control and Prevention, Uppsala County Council, Sweden. \\ ${ }^{2}$ Department of Medical Sciences, Uppsala University, Sweden. \\ ${ }^{3}$ Uppsala Clinical Research Center, Uppsala, Sweden.
}

\begin{abstract}
Background: Descriptive analyses of influenza A (H1N1) 2009 were conducted on the pandemic (H1N1) 2009 influenza cases in Uppsala County. Uppsala County, situated close to the Stockholm urban area, has approximately 330000 inhabitants. The pandemic influenza became a notifiable disease on May 2009 under the Swedish Communicable Disease Act, which implies that suspected influenza cases must be laboratory-verified and reported to the county medical officer and to the Swedish Institute for Infectious Disease Control.

Methods: The analyses were performed using the patients' unique identification code via an electronic database system (eCRF) complemented by the patients' records.

Results: In all, 456 confirmed influenza cases were reported from June 2009 to the end of December 2009. The main outbreak was restricted to 5 weeks in the autumn of 2009 when $82 \%$ of the cases were reported. Thirty-five percent of the patients had underlying medical risk conditions. No difference in symptoms was found between patients with underlying medical conditions and patients without risk. However, $64 \%$ of the patients with underlying medical conditions received antiviral therapy compared with $24 \%$ for the other patients. Patients with medical conditions received the vaccination in the beginning of the epidemic, whereas patients without risk received the vaccination at a later time. Forty-nine patients admitted vaccination, and of these, 46 received the vaccination 1week or less before onset of illness. The study showed that the epidemiological and clinical picture did not differ from seasonal influenza and that younger age groups were more affected than older age groups (i.e., older persons had some protection, probably through earlier contact with similar virus strains).

Conclusions: The pandemic-based information from national and international authorities was crafted in the shadow of the threat from H5N1 avian influenza and was not in proportion to mainly mild-to-moderate illness caused by the $2009 \mathrm{H} 1 \mathrm{N1}$ pandemic.
\end{abstract}

Keywords: Pandemic influenza, A (H1N1) 2009, notified cases, vaccine coverage

\section{Background}

During the spring of 2009, a novel strain of influenza A (H1N1) virus appeared globally. The new swine-origin influenza strain was genetically distinct from seasonal influenza virus and classified by WHO as a novel influenza virus strain and as a pandemic influenza outbreak [1].

The novel influenza A (H1N1) virus was identified in Mexico, the USA, Canada and elsewhere [2]. The first cases, associated with a number of unexpected deaths in younger persons, were registered in Mexico [3]. Early findings of severe pneumonia and deaths associated with the novel swine-origin influenza A (H1N1) were reported. However, several uncertainties remained about the viral strain on the novelty of the virus, its transmissibility and virulence, including the pandemic potential of the virus. Later, it became evident that although the pandemic virus of 2009 was novel, it was not a new type, being classified as influenza $A(H 1 N 1)$ subtype. This swine-lineage influenza virus spread in the USA and a rapid global dispersion of the virus occurred soon thereafter. By September 2009, this influenza infection had been discovered in 191 countries [4]. The first cases in Europe were reported in the UK in April 2009 [5]. Reports indicated that younger age groups (under the age of 18 years) were most affected [6]. It was soon evident that the pandemic influenza A (H1N1) 2009virus generally only caused mild illness not different from seasonal influenza. In addition, older individuals seemed to have partial immunity because similar strains had been previously circulating, whereas younger people lacked immunity and were accordingly more affected [7]. Several studies have reported cross-reactive antibody responses to the pandemic $\mathrm{H} 1 \mathrm{~N} 1$ influenza virus in the elderly [8]. Reports from the USA indicate that more than $30 \%$ of the elderly population had neutralizing antibodies to the new $A$ H1N1 2009 virus strain [9]. Moreover, post-pandemic analyses found that relatively few persons $\geq 65$ years were infected during the epidemic, i.e., the majority of the clinical cases occurred in younger age groups [10].

In May 2009, the pandemic influenza A (H1N1) was included in the Swedish Communicable Disease Act, which states that all suspected influenza cases had to be laboratory-verified and reported. 
Sylvan et al. Research Journal of Infectious Diseases 2013,

Table 1. Patients (159) with one or more underlying medical condition.

\begin{tabular}{lcc}
\hline Condition & Number & $\begin{array}{c}\text { \% of 448 } \\
\text { patients }\end{array}$ \\
\hline Medically treated asthma & 79 & 18 \\
Chronic pulmonary or cardiovascular disease & 23 & 5 \\
Immunodeficiency (including HIV) & 18 & 4 \\
Pregnancy & 16 & 4 \\
Diabetes & 9 & 2 \\
Chronic obstructive pulmonary disease & 8 & 2 \\
Extreme obesity & 7 & 2 \\
Chronic renal or liver disease & 6 & 1 \\
Children <2 years and with chronic diseases & 3 & 1 \\
\hline
\end{tabular}

Since 1997, in accordance with the Swedish national policy, persons $\geq 65$ years or persons of all ages with underlying medical conditions have been offered vaccination free of charge against expected seasonal influenza strains. Additional to the yearly vaccination distributed to eligible people against the seasonal influenza in the autumn of 2009, the Swedish National Board of Health and Welfare determined that all individuals, including children, should be offered two doses of the new monovalent A (H1N1) 2009 vaccine from GlaxoSmithKline(GSK,Pandemrix) as soon as this vaccine was available. Already before the outbreak of the pandemic influenza 2009, the National Board of Health and Welfare had an agreement with the vaccine producer to purchase enough vaccine to cover the whole population of Sweden in case of an influenza outbreak. This arrangement was made principally in case of an outbreak of avian influenza (H5N1).

Further, from May 2009, as part of the Swedish strategy to limit the transmission of the pandemic influenza and in accordance with the WHO recommendation, an antiviral drug (Oseltamivir) was recommended for all patients with influenzalike symptoms or who had been in contact with a verified A (H1N1) influenza case or who had travelled in affected areas $[11,12]$. This recommendation was later modified, however, when the containment policy of influenza was no longer feasible.

The aim of this study was to emphasize the importance of evaluating influenza outbreaks cautiously by not exaggerating its significance. International and national health authorities must be particularly thoughtful when interpreting the epidemiological impact of an outbreak. We would also like to underline that the vaccine has to be tested and available at the time of an outbreak.

\section{Methods}

Population

Descriptive analyses of pandemic influenza A (H1N1) 2009 were conducted in Uppsala County, a region with approximately 330000 inhabitants situated close to the Stockholm urban area. In all, 448 laboratory-confirmed influenza A (H1N1)
2009 cases were documented. Of the 448 verified influenza cases, 159 (35\%) belonged to one of the National Board of Health defined medical risk categories (Table 1). These cases included medically treated asthma, chronic pulmonary or cardiovascular disease, diabetes, neurological diseases, children less than 2 years of age, children with chronic diseases/ handicaps and pregnant women. Other cases included were immunodeficiency, including HIV and extreme obesity (body mass index, $\mathrm{BMI}>40$ ).

\section{Data collection and surveillance}

The pandemic influenza strain became a notifiable disease under the Swedish Communicable Disease Act on 15 May 2009 , which entails that specimens had to be obtained from all suspected influenza cases (such as fever $>38^{\circ} \mathrm{C}$ or flu-like illness or in contact with a suspected pandemic influenza case). Further, all laboratory-confirmed cases should be reported to the county medical officer and the Swedish Institute for Infectious Disease Control. Information pertaining to onset date, underlying medical conditions, probable source of infection (Sweden or abroad), sample date, age, sex, symptoms, duration of illness, antiviral treatment, complications, antibiotic treatment and vaccination with the new monovalent $A S 03$-adjuvanted influenza $A(H 1 N 1)$ vaccine was collected. In accordance with the WHO recommendation, antiviral drugs were offered to all patients with verified influenza A (H1N1) infection or to patients who had at least two influenza-like symptoms. In addition, special attention was directed toward patients with underlying medical risk conditions. The laboratory-confirmed influenza cases were reported using the unique national identification number (Swedish: personnummer) complemented by patient records. The analyses were performed via an electronic database system (eCRF) and these data were entered into a case report database system (SAS/Pheedlt ${ }^{\oplus}$ ). The present analysis outlines a statistical description of study variables. In some of the tables and figures a few individuals are missing because relevant information was lacking. Under the Communicable Diseases Act, the county medical officer plans, organizes and runs communicable disease control and works to ensure efficiency, coordination and standardization of this work. The Communicable Diseases Act satisfies all reasonable requirements for taking into account the respect for equal value of all people and individual statutory rights. Written informed consent of the study population was not necessary because this study did not modify the existing diagnosis or the therapeutic strategy. Moreover, all data samples were under code and could not be associated with an identifiable individual by the research team.

\section{Vaccine and vaccination campaign}

In Sweden, Pandemrix was given free of charge to the general population. All persons were offered the vaccination as soon as it was available. Initially, two doses of the vaccine $(0.5$ 


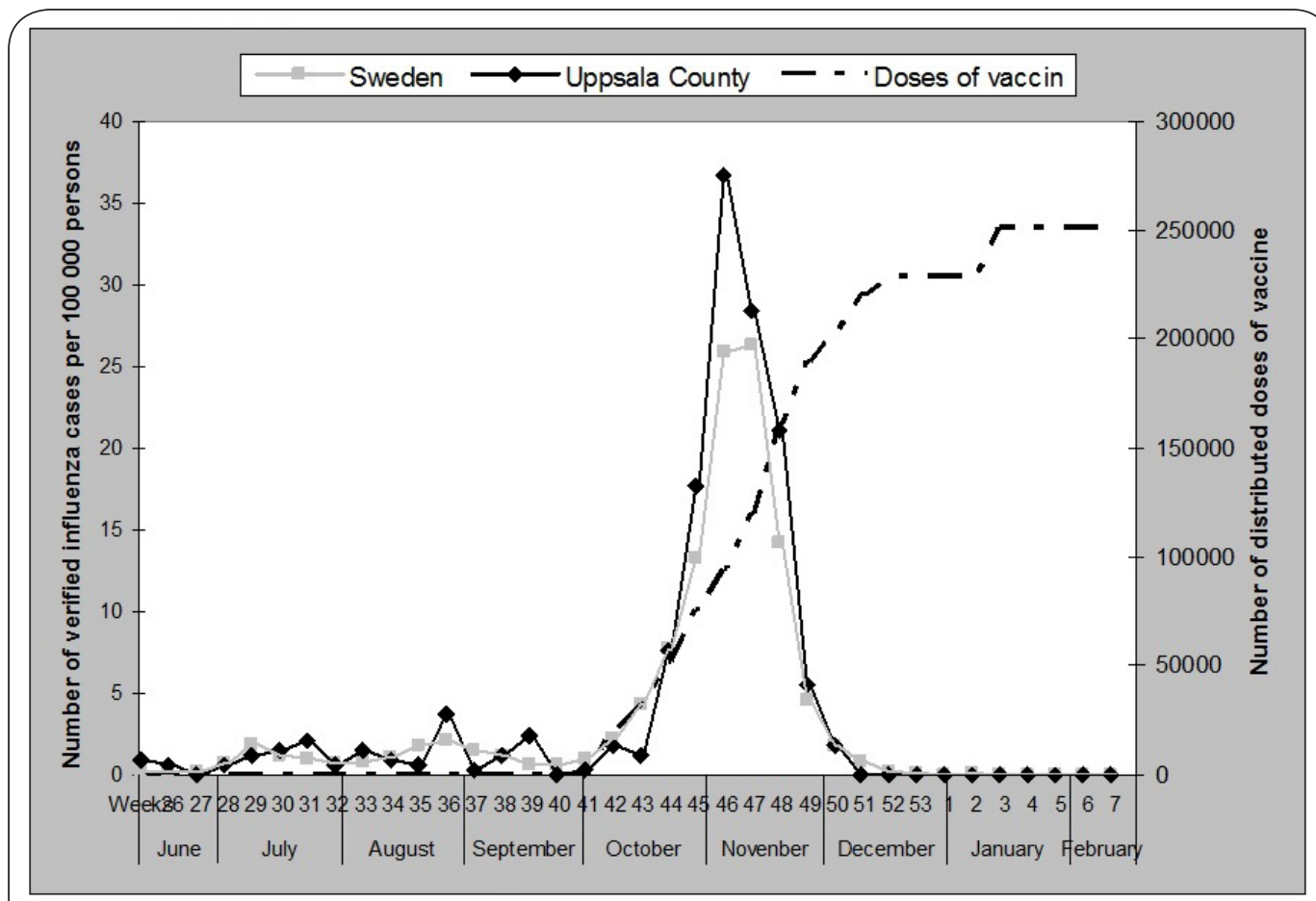

Figure 1. Pandemic influenza A (H1N1) 2009 in Uppsala County and Sweden.

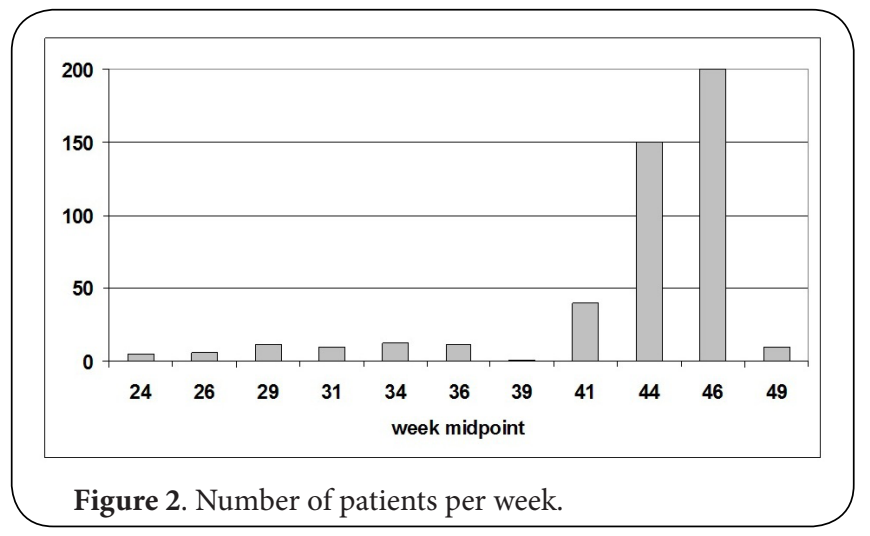

$\mathrm{ml} /$ dose) were recommended for all persons 13 years and older and a half a dose for children 3-12 years. Because of manufacturing and distribution problems, the first doses of the vaccine were not distributed before the middle of October (week 42) 2009. Those with underlying medical risk conditions and young children were initially vaccinated. General vaccination of adults was started later, approximately after week 47. At the peak of the epidemic in the middle of November 2009, roughly 100000 doses of the vaccine had been distributed (but not yet given) (Figure 1).

\section{Statistical methods}

Continuous variables are presented with mean, standard deviation (SD), minimum value, median, maximum value and interquartile range (IQR). Categorical variables are shown in tables with absolute frequency and percent. Statistical comparisons between groups were made with non-parametric tests. The level of statistical significance was set to $p<0.05$. All calculations were performed with $\mathrm{SAS}^{\circledR}{ }^{\circledR}$ v.9.2 (SAS Institute Inc., Cary, NC, USA).

\section{Results}

Totally, 448 laboratory-verified pandemic influenza A (H1N1) cases were investigated from the beginning of June 2009 to the end of December 2009. The first sporadic cases of influenza $\mathrm{A}(\mathrm{H} 1 \mathrm{~N} 1)$ in Uppsala County were detected in June 2009. The main epidemic occurred during 5 weeks (from the end of October until the end of November) when 375 (82\%) of the influenza cases were reported. Before and after these weeks, only sporadic cases were reported (Figure 2). Most cases were domestically infected, with only 35 persons (8\%) reporting that they had acquired the infection abroad (defined as being abroad $<1$ week before symptom debut); 102 patients reported that they had not been abroad; and information was lacking for 320 patients.

Infections acquired abroad had mainly occurred in June and July 2009. During the peak of the pandemic in November (week 46), the incidence increased to 37.5 verified influenza H1N1 cases per 100000 persons in Uppsala County, which was higher than the average incidence in Sweden (Figure 1).

Of the 448 laboratory-verified pandemic influenza A (H1N1) patients, 268 were attending primary health care units and 
Sylvan et al. Research Journal of Infectious Diseases 2013,

http://www.hoajonline.com/journals/pdf/2052-5958-1-6.pdf

Table 2. Age distribution (years).

\begin{tabular}{cccccccc}
\hline \multicolumn{1}{c}{ Analysis Variable: age } \\
\hline & & $\begin{array}{c}\text { Standard } \\
\text { n }\end{array}$ & Mean & Lower & \multicolumn{3}{c}{ Upper } \\
deviation & Minimum & Quartile & Median & Quartile & Maximum \\
\hline 440 & 28.4 & 17.4 & 0.0 & 15.0 & 25.0 & 41.0 & 76.0 \\
\hline
\end{tabular}

Table 3. Distributions of symptoms by age groups (number of patients, \%).

\begin{tabular}{|c|c|c|c|c|c|c|}
\hline \multirow{2}{*}{$\begin{array}{l}\text { Symptom } \\
\text { Number of patients }\end{array}$} & \multicolumn{2}{|c|}{$\leq 18$ years } & \multicolumn{2}{|c|}{$>18$ years } & \multicolumn{2}{|c|}{ Total } \\
\hline & 148 & $(\%)$ & 292 & $(\%)$ & 440 & $(\%)$ \\
\hline Fever $(>37.5 \mathrm{C})$ & 143 & $(97)$ & 251 & $(86)$ & 394 & $(90)$ \\
\hline Cough & 108 & ( 73 ) & 228 & ( 78 ) & 336 & $(76)$ \\
\hline Muscle/joint aches & 50 & $(34)$ & 176 & $(60)$ & 226 & $(51)$ \\
\hline Chest pain/shortness of breath & 36 & $(24)$ & 122 & $(42)$ & 158 & $(36)$ \\
\hline Sore throat & 54 & $(36)$ & 86 & $(29)$ & 140 & $(32)$ \\
\hline Head ache & 45 & $(30)$ & 114 & ( 39 ) & 159 & $(36)$ \\
\hline Vomiting & 33 & $(22)$ & 34 & $(12)$ & 67 & $(15)$ \\
\hline Seizures & 26 & $(18)$ & 49 & $(17)$ & 75 & $(17)$ \\
\hline No symptoms & 3 & (2) & 17 & (6) & 20 & (5) \\
\hline
\end{tabular}

Table 4. Distribution of symptoms in patients belonging to medical risk groups and those without risk.

\begin{tabular}{llccccccccccc}
\hline & \multicolumn{11}{c}{ Number of symptoms } \\
\hline & No & $\mathbf{0}$ & $\mathbf{1}$ & $\mathbf{2}$ & $\mathbf{3}$ & $\mathbf{4}$ & $\mathbf{5}$ & $\mathbf{6}$ & $\mathbf{7}$ & $\mathbf{8}$ & $\mathbf{9}$ & $\mathbf{1 0}$ \\
\hline Risk & 159 & 5 & 4 & 23 & 32 & 36 & 37 & 14 & 4 & 2 & 2 & 0 \\
group & $\%$ & 3.4 & 2.5 & 14.4 & 20.1 & 22.6 & 23.3 & 8.8 & 2.5 & 1.3 & 1.3 & -- \\
\hline \multirow{2}{*}{ No } & 287 & 21 & 6 & 25 & 64 & 57 & 56 & 27 & 19 & 10 & 1 & 1 \\
risk & $\%$ & 7.3 & 2.1 & 8.7 & 22.3 & 19.9 & 19.5 & 9.4 & 6.6 & 3.5 & 0.4 & 0.4 \\
\hline Total & $\mathbf{4 4 6}$ & $\mathbf{2 6}$ & $\mathbf{1 0}$ & $\mathbf{4 8}$ & $\mathbf{9 6}$ & $\mathbf{9 3}$ & $\mathbf{9 3}$ & $\mathbf{4 1}$ & $\mathbf{2 3}$ & $\mathbf{1 2}$ & $\mathbf{3}$ & $\mathbf{1}$ \\
\hline
\end{tabular}

Table 5. Patients who received antiviral and/or anti-bacterial treatment.

\begin{tabular}{lccc}
\hline & & Antiviral & Antibiotic \\
\hline & Number & treatment & treatment \\
\hline \multirow{2}{*}{ Risk group } & 159 & 102 & 37 \\
& $\%$ & 64.2 & 23.3 \\
\hline \multirow{2}{*}{ No risk } & 287 & 70 & 54 \\
& $\%$ & 24.4 & 18.8 \\
\hline Totalt & $\mathbf{4 4 6}$ & $\mathbf{1 7 2}$ & $\mathbf{9 1}$ \\
\hline
\end{tabular}

188 were visiting the University Hospital in Uppsala. Sixtytwo patients $(13.5 \%)$ were hospitalized, which is 18.8 per 100000 inhabitants; four of these patients were admitted to an intensive care unit (1.2 per 100000 persons). Two deaths occurred ( 0.6 per 100000 inhabitants): one patient who needed ECMO (extracorporeal membranoxygenering) treatment died after 16 days with several complications while the other patient died at home without having sought medical care. Both had underlying medical conditions. A slightly lower

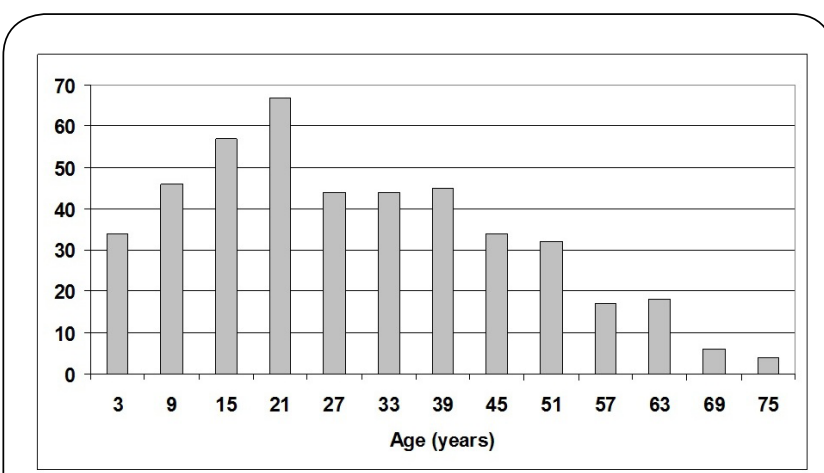

Figure 3. Number of patients distributed by age.

number of women (48.5\%) than men (51.5\%) were verified with pandemic influenza.

The age distribution showed that younger persons were predominately affected (Figure 3 ) (mean age, 28 years; SD, 17.4 years; median age, 25 years; IQR, $15-41$ years). Only $2 \%$ of the influenza cases were $\geq 65$ years (Table 2), whereas $39 \%$ were $\leq 18$ years. The symptoms were generally mild and not different from seasonal influenza infection. For all age groups, the most common symptom was fever, followed by productive cough and muscle/joint aches (Table 3). Comparing persons $\leq 18$ years with those $>18$ years, significantly more persons $>18$ years had muscle/joint aches $(p<0.001)$.

Chest pain and shortness of breath $(p<0.01)$ were more common in those $>18$ years, whereas vomiting was more common among the younger patients $(p<0.02)$. Thirty-five percent of the patients had at least one underlying medical risk condition (Table 1). The most common underlying factor in the medical risk patients was medically treated asthma $(50 \%)$, followed by chronic pulmonary and heart disease (14\%). Of the verified influenza cases, 172 (39\%) patients received the antiviral drug oseltamivir (Roche USA), of which 79 (48\%) were given the antiviral drug within 48 hours. Figure 4 shows the time interval from symptom debut to onset of antiviral therapy (median, 3 days; SD, 2.4 days; IQR, 1.0-4.0 days). There was no significant difference in severity or in number of symptoms between patients belonging to a defined medical risk category and patients without a risk factor (Table 4). However, $64 \%$ of the patients with underlying medical condition received the antiviral therapy compared with only $24 \%$ in patients without a medical condition (Table 5). No significant differences were observed between the patients with medical condition and the patients with bacterial complication (Table 5). 


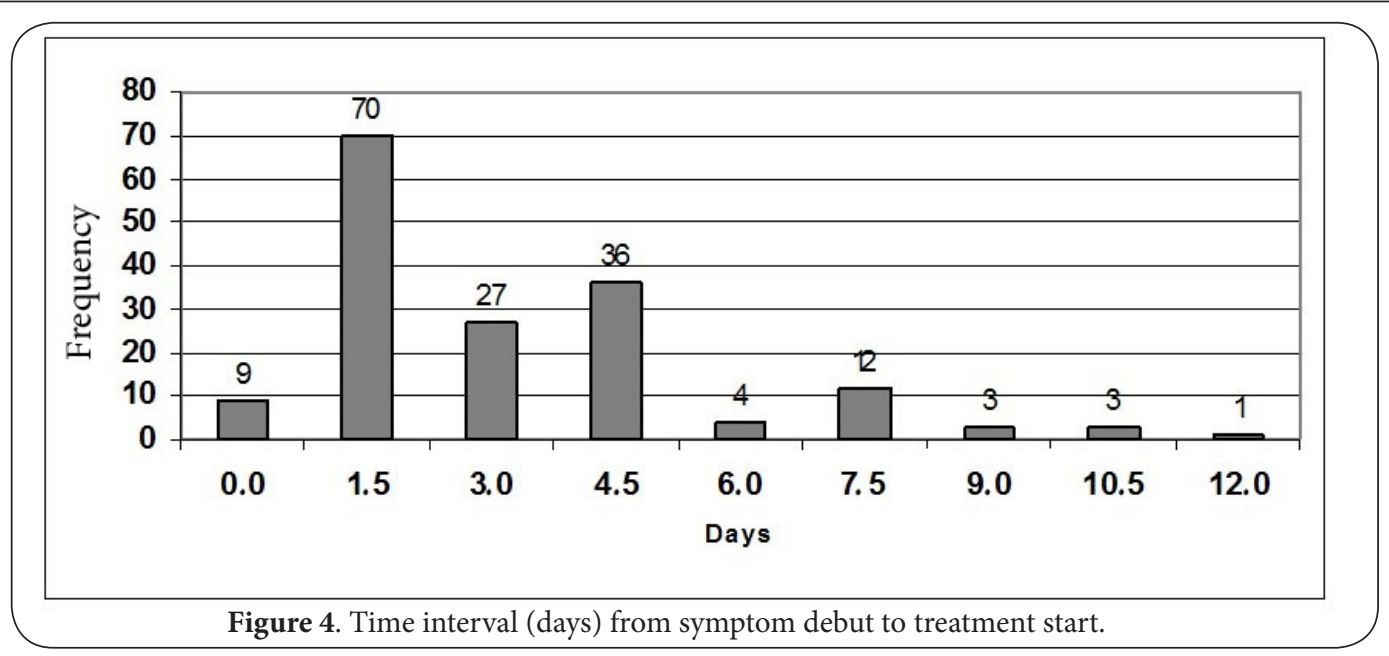

Vaccination of the general population was introduced late (week 47) in relation to the peak of the pandemic. It was established that 49 of the verified influenza cases had received Pandemrix. In 46 patients the vaccine had been given less than 1 week before onset of illness. Vaccine failure was observed in three patients who had received the monovalent vaccine more than 3 weeks before onset of illness.

\section{Discussion}

The pandemic influenza outbreak in Uppsala County was evaluated from the first cases in the beginning of June to the end of December 2009.In our opinion most of the clinical cases in the pandemic influenza in Uppsala County were reported because of the high media attention and because the pandemic influenza became a notifiable disease under the Swedish Communicable Disease Act. The main epidemic was limited to 5 weeks in the autumn of 2009 when most (82\%) of the cases occurred.

In Uppsala County 448 verified influenza A (H1N1) cases were diagnosed: $62(13.8 \%)$ patients were hospitalized and $2(0.4 \%)$ with underlying medical conditions died. Notable was that persons with medically treated asthma were most affected and prone to seek medical attendance.

For the majority of cases, the symptoms and severity were mild and comparable with what is observed in seasonal influenza and consistent with other reports $[7,8]$. Gastroint-estinal symptoms were more frequent, especially in younger age groups. However, gastrointestinal symptoms might be more common than is generally recognized because adolescents do not normally seek medical care for vomiting or diarrhea. Because the majority of persons were younger (mean age, 28 years) with only $2 \% \geq 65$ years, the age distribution in our study differed from what is typically reported in seasonal influenza. One explanation for the discrepancy in the age distribution could be that the attention in the media led to younger people seeking medical care, something they normally would not do. The number of young people taken ill from influenza is higher than usually assumed because they tend not to seek medical attention to the same extent as older people. However, the main transmission of influenza virus occurs among schoolchildren and in day care centers. Another important explanation to the discrepancy in the age distribution was that older persons had antibody responses against the influenza $A(\mathrm{H} 1 \mathrm{~N} 1)$ virus, most likely because they had previously been infected with similar virus strains. Several studies have verified cross-reactive antibodies against the pandemic A (H1N1) virus. One study, performing hemagglutination-inhibition and neutralization tests, demonstrated that persons 60 years and older had cross-reactive antibodies to A (H1N1) 2009 [9]. The influenza A (H1N1) viruses have been circulating before 1946, suggesting that elderly persons that have been exposed to this virus or similar strains have some protection against the virus strain [10]. A high degree of antigenic and genetic similarity to an influenza outbreak in the USA and Europe in 1976 has been shown [12]. Further, younger persons had little evidence of cross-reactive antibodies to the $2009 \mathrm{H} 1 \mathrm{~N} 1$ pandemic virus, whereas older individuals had pre-existing antibodies [13]. Reports from the USA have confirmed that older populations had some protection against the pandemic virus $[\mathbf{9 , 1 4}]$. In metropolitan France children and adolescents were found to lack antibodies to the 2009 influenza A (H1N1) before the pandemic. In contrast, persons aged $>65$ years had crossreactive antibodies before the pandemic [15]. Post-pandemic clinical cases and seroconversions were mostly detected in younger individuals (few of the elderly showed signs of having been infected) [15]. Moreover, cross-reactive antibodies against seasonal $\mathrm{H} 1 \mathrm{~N} 1$ viruses were found to neutralize the 2009 pandemic influenza A (H1N1) virus in individuals 60 years and older, which might have contributed to lowering the prevalence of the 2009 pandemic [16]. Evidence that the elderly had some kind of protection was demonstrated in the Taiwanese population in stored sera from donors born between 1917 and 2008 [17]. Combined, these data provide evidence that older people worldwide were less susceptible to the new pandemic influenza strain because it had been 
circulating for some time before 2009. Particularly noteworthy is that the main reason for WHO to classify the influenza A (H1N1) 2009 pandemic was that it was an entirely new strain.

In accordance with WHO recommendations, 39\% of patients with verified pandemic influenza in Uppsala received an antiviral drug (oseltamivir), treatment that might have contributed to modifying the illness [18]. No significant differences in symptoms or degree of illness were noted between medical risk groups and those without risk. However, in patients with underlying medical conditions $64 \%$ received the antiviral treatment compared with $24 \%$ in those without a medical condition (Table 5). During the pandemic 2009 in the USA, hospitalizations were believed averted because of the effect of the antiviral drug [19], indicating benefits of antiviral therapy, particularly for individuals with underlying medical conditions [20]. However, receiving the antiviral drugs early in the course of the disease is crucial [21]. Data from hospitalized patients in the USA suggest that the use of antiviral drugs was beneficial when initiated early(i.e., within the first 2 days of illness). The data also suggest that patients were less likely to die if therapy was started within 48 hours after onset of symptoms [6,22]. During the pandemic in Uppsala County, the antiviral therapy was given relatively soon after symptom debut ( $48 \%$ of those given antiviral therapy received it within 48 hours, mean 3.1 days). No significant difference was found in bacterial complications between individuals with and without underlying medical conditions. Because the vaccination started late in relation to the peak of the epidemic, many persons, especially those without risk, had not received the vaccination in time to be protected. Forty-nine of the patients with laboratory-confirmed influenza admitted being vaccinated; of these 49 patients, 46 had received the vaccine $<1$ week before they had fallen ill with the influenza.

Vaccine failures were documented in only three patients. Consequently, the effectiveness of the vaccine is difficult to evaluate. However, a prospective population-based cohort study carried out in Stockholm County, Sweden indicated that the monovalent AS03-adjuvanted influenza vaccine was highly protective against pandemic influenza [23]. Other studies, using the same adjuvanted vaccine, have confirmed its efficiency $[\mathbf{2 4 , 2 5}$. On the other hand, countries with little vaccination efforts did not differ in influenza-caused morbidity or death compared with Sweden. Already in August 2009, the peak of the influenza had passed in Australia, New Zeeland and Chile and information about the development of the pandemic was available [26-28]. The epidemic had started in June and culminated during 4 weeks in July. The course of the epidemic was similar in these three countries, i.e., it was of short duration and did not differ from seasonal influenza. Concerning population density and medical service, these countries are comparable with Sweden. In case of an (H5N1) influenza outbreak the Swedish authorities had an agreement with the vaccine producer to purchase influenza vaccine to support the new recommendation to vaccinate the entire Swedish population. Regardless of the development of the epidemic in the Southern Hemisphere, the Swedish authorities had a binding agreement to complete the vaccine commitment. After the mild outcome of the pandemic, the vaccination strategy has been questioned and concerns have been raised about the cost of the vaccine as well as the necessity of two doses of vaccine for the whole population [29]. Despite that no vaccine had been available in the Southern Hemisphere in 2009, the course and outcome of the epidemic were comparable to the development in Sweden. Moreover, doubt has recently been cast on the possible side effects of mass-vaccination with an untested vaccine. In Sweden, an increase of young people with narkolepsia following vaccination with Pandemrix has been observed [30].

\section{Conclusions}

The outbreak of the pandemic A (H1N1) influenza was limited to a few weeks in the late autumn of 2009. The epidemiological and clinical features did not differ from seasonal influenza viruses. Transmission mainly occurred between younger age groups. Older individuals had some protection, probably because similar influenza viral strains have previously been circulating. The intensive media coverage of the pandemic based on information from national and international authorities was not in proportion to its severity, extension or effect on public welfare.

\section{Competing interests}

The authors declare that they have no competing interests.

\section{Authors' contributions}

SPES, BS, KP designed the study, collected, analyzed and interpreted the data and drafted the manuscript. LB participated in the design of the study, performed the statistical analysis and helped to draft the manuscript. All authors read and approved the final manuscript.

\section{Acknowledgement}

We are grateful to Inger Tverin, Bodil Ardung and Johan Hedlund for their help during this investigation.

\section{Publication history}

EIC: Istiaq Quadri, King Abdul Aziz University, Jeddah, Saudi Arabia. Received: 25-Jun-2013 Revised: 14-Aug-2013

Accepted: 20-Aug-2013 Published: 27-Aug-2013

\section{References}

1. Centres for Disease Control and Prevention. Outbreak of swine-origin influenza A (H1N1) virus infection - Mexico, March-April 2009. MMWR Morb Mortal Wkly Rep. 2009; 58:467-70. | Article I PubMed

2. Dawood FS, Jain S, Finelli L, Shaw MW, Lindstrom S, Garten RJ, Gubareva LV, Xu X, Bridges CB and Uyeki TM. Mergence of novel swine-origin influenza A (H1N1) virus in humans. The New England Journal of Medicine. 2009; 360:2605-15. | Article | PubMed

3. Chowell G, Bertozzi SM, Colchero MA, Lopez-Gatell H, Alpuche-Aranda $C$, Hernandez $M$ and Miller MA. Severe respiratory disease concurrent with the circulation of H1N1 influenza. N Engl J Med. 2009; 361:674-9. | Article I PubMed

4. World Health Organization. Pandemic (H1N1) 2009- update 67. Geneva: 
Sylvan et al. Research Journal of Infectious Diseases 2013,

Accessed October 6, 2009. I Website

5. McLean E, Pebody RG, Campbell C, Chamberland M, Hawkins C, Nguyen-Van-Tam JS, Oliver I, Smith GE, Ihekweazu C, Bracebridge S et al. Pandemic (H1N1) 2009 influenza in the UK: clinical and epidemiological findings from the first few hundred (FF100) cases. Epidemiol Infect. 2010; 138:1531-41. | Article | PubMed

6. Jain S, Kamimoto L, Bramley AM, Schmitz AM, Benoit SR, Louie J, Sugerman DE, Druckenmiller JK, Ritger KA, Chugh R et al. Hospitalized patients with 2009 H1N1 influenza in the United States, April-June 2009. N Eng/ J Med. 2009; 361:1935-44. | Article | PubMed

7. Girard MP, Tam JS, Assossou OM and Kieny MP. The 2009 A (H1N1) influenza virus pandemic: A review. Vaccine. 2010; 28:4895-902. | Article | PubMed

8. Nicholson KG. Clinical features of influenza. Semin Respir Infect. 1992; 7:26-37. | PubMed

9. Garten RJ, Davis CT, Russell CA, Shu B, Lindstrom S, Balish A, Sessions WM, Xu X, Skepner E, Deyde V et al. Antigenic and genetic characteristics of swine-origin 2009 A(H1N1) influenza viruses circulating in humans. Science. 2009; 325:197-201. | Article | PubMed Abstract | PubMed Full Text

10. Hancock K, Veguilla V, Lu X, Zhong W, Butler EN, Sun H, Liu F, Dong L, DeVos JR, Gargiullo PM, Brammer TL, Cox NJ, Tumpey TM and Katz JM. Cross-reactive antibody responses to the 2009 pandemic H1N1 influenza virus. N Eng/J Med. 2009; 361:1945-52. | Article | PubMed

11. European Centre for Disease Prevention and Control (EDCD). On public health use of influenza antivirals during influenza pandemics (with particular reference to the pandemic (H1N1) 2009) Outbreak. | Website

12. World Health Organization. WHO Guidelines for pharmacological management of pandemic (H1N1) 2009 influenza and other influenza viruses. I Website

13. Kilbourne ED. Perspectives on pandemics: a research agenda. J Infect Dis. 1997; 176 Suppl 1:S29-31. | Article | PubMed

14. Skountzou I, Koutsonanos DG, Kim JH, Powers R, Satyabhama L, Masseoud F, Weldon WC, Martin Mdel P, Mittler RS, Compans R and Jacob J. Immunity to pre-1950 H1N1 influenza viruses confers crossprotection against the pandemic swine-origin 2009 A (H1N1) influenza virus. J Immunol. 2010; 185:1642-9. | Article | PubMed

15. Center for Disease Control and Prevention. 2009. Serum cross-reactive antibody response to a novel influenza $A$ (H1N1) virus after vaccination with seasonal influenza vaccine. MMWR Morb Mortal Wkly Rep. 2009; 58:521-4. | Article | PubMed

16. Delangue J, Salez N, Ninove L, Kieffer A, Zandotti C, Seston M, Lina B, Nougairede A, Charrel R, Flahault A and de Lamballerie X. Serological study of the 2009 pandemic due to influenza A H1N1 in the metropolitan French population. Clin Microbiol Infect. 2012; 18:177-83. | Article | PubMed

17. Lemaitre M, Leruez-Ville M, De Lamballerie XN, Salez N, Garrone $P$, Fluckiger AC, Klatzmann D and Carrat F. Seasonal H1N1 2007 influenza virus infection is associated with elevated pre-exposure antibody titers to the 2009 pandemic influenza A (H1N1) virus. Clin Microbiol Infect. 2011; 17:732-7. | Article | PubMed

18. Chi CY, Liu CC, Lin CC, Wang HC, Cheng YT, Chang CM and Wang JR. Preexisting antibody response against 2009 pandemic influenza H1N1 viruses in the Taiwanese population. Clin Vaccine Immunol. 2010; 17:1958-62. | Article | PubMed Abstract | PubMed Full Text

19. Aoki FY and Boivin G. Influenza virus shedding: excretion patterns and effects of antiviral treatment. J Clin Virol. 2009; 44:255-61. | Article | PubMed

20. Atkins CY, Patel A, Taylor TH, Jr., Biggerstaff M, Merlin TL, Dulin SM, Erickson BA, Borse RH, Hunkler R and Meltzer MI. Estimating effect of antiviral drug use during pandemic (H1N1) 2009 outbreak, United States. Emerg Infect Dis. 2011; 17:1591-8. | Article | PubMed Abstract | PubMed Full Text

21. Donaldson LJ, Rutter PD, Ellis BM, Greaves FE, Mytton OT, Pebody RG and Yardley IE. Mortality from pandemic A/H1N1 2009 influenza in England: public health surveillance study. BMJ. 2009; 339:b5213. | Article | PubMed Abstract | PubMed Full Text
22. Aoki FY and Boivin G. Influenza virus shedding: excretion patterns and effects of antiviral treatment. J Clin Virol. 2009; 44:255-61. | Article | PubMed

23. Centers for Disease Control and Prevention. Surveillance for pediatric deaths associated with 2009 pandemic influenza A (H1N1) virus infection - United States, April-August 2009. MMWR Morb Mortal Wkly Rep. 2009; 58:941-7. | Article | PubMed

24. Ortqvist A, Berggren I, Insulander M, de Jong B and Svenungsson B. Effectiveness of an adjuvanted monovalent vaccine against the 2009 pandemic strain of influenza A(H1N1)v, in Stockholm County, Sweden. Clin Infect Dis. 2011; 52:1203-11. | Article | PubMed

25. Walter D, Bohmer MM, Heiden M, Reiter S, Krause $G$ and Wichmann $\mathrm{O}$. Monitoring pandemic influenza $A(\mathrm{H} 1 \mathrm{~N} 1)$ vaccination coverage in Germany 2009/10 - results from thirteen consecutive cross-sectional surveys. Vaccine. 2011; 29:4008-12. | Article | PubMed

26. Bishop JF, Murnane MP and Owen R. Australia's winter with the 2009 pandemic influenza A (H1N1) virus. N Engl J Med. 2009; 361:2591-4. I Article | PubMed

27. Kotsimbos T, Waterer G, Jenkins C, Kelly PM, Cheng A, Hancox RJ, Holmes M, Wood-Baker R, Bowler S, Irving L and Thompson P. Influenza A/ H1N1_09: Australia and New Zealand's winter of discontent. Am J Respir Crit Care Med. 2010; 181:300-6. | Article | PubMed

28. Dabanch PJ and Perret PC. Influenza pandemic of novel (H1N1) 2009 virus in Chile. How we dealt with the first wave? Rev Chilena Infectol. 2009; 26:307-10. | Article | PubMed

29. Van Buynder PG, Dhaliwal JK, Van Buynder JL, Couturier C, MinvilleLeblanc M, Garceau R and Tremblay FW. Protective effect of single-dose adjuvanted pandemic influenza vaccine in children. Influenza Other Respi Viruses. 2010; 4:171-8. | Article | PubMed

30. Swedish Medical Products Agency publishes report from a case. Inventory study on Pandemrix vaccination and development of narcolepsy with cataplexy. Euro Surveill. 2011; 16:pii=19904. I Website

Citation:

Sylvan SPE, Christenson B, Pauksen K and Berglund L. Clinical and epidemiological findings in patients with pandemic A (H1N1) 2009 influenza in uppsala county, Sweden. Res J Infect Dis. 2013; 1:6.

http://dx.doi.org/10.7243/2052-5958-1-6 